\title{
ARTICLE
}

\section{Detection of acoustic wave generated by Baganuur mining explosion}

Tungalag Lkhagva*, Bayarsaikhan Chimedtseren and Narmandakh Adiyasuren

Department of Seismology, Institute of Astronomy and Geophysics, Mongolian Academy of Sciences, Ulaanbaatar, Mongolia

ARTICLE INFO: Received: 23 Oct, 2020; Accepted: 23 Aug, 2021

Abstract: We analyzed all available recorded infrasound data and determined the station detection capability in Mongolia. While in the winter times, we continuously detect acoustic signals from blasts at the Baganuur open-pit mine (150 km from infrasound I34MN station), which we rarely registered during the summer times. A previous study has shown that the noise level increased by $5 d B-10 d B$ in the summer, whichaffected the detection capability of the stations.

On the other hand, this could be connected to infrasound propagation model difference between winter and summer times. To verify this phenomenon, we installed a new infrasound IBHM station in a forest area at a distance of $350 \mathrm{~km}$ from the Baganuur mine area. When we compared the background noise level of the two stations, the noise level at the temporary station was lower than the permanent one, which allowed us to compare winter and summer time registered infra wave characteristics. With the comparison observed and modeled, apparent velocity suggested that winter and summer time detection difference could be due to the propagation model of infrasound wave itself.

Keywords: Infrasound; mine blasts;

\section{INTRODUCTION}

According to the agreement between the Mongolian Government and the Comprehensive nuclear-test-ban treaty organization (CTBTO) I34MN Infrasound station with 4-element array was installed at a place $55 \mathrm{~km}$ north-west of the city of Ulaanbaatar. This station was certified in December 2000 by CTBTO. It was upgraded to 8 -element array in 2006, which improved the station's detection capability. Today, the Infrasound network station continuously detects acoustic signals of natural phenomena, such as, meteorites, microbaroms, meteorological events, and man-made signals, such as explosions, rocket launches, military field shootings, city noise. [1][2]. At the I34MN station, it has been observed that the number of detected events increased during the winter times as compared to the summer season [2]. This seasonal variation was previously explained as the difference between noise level change from winter to summer.

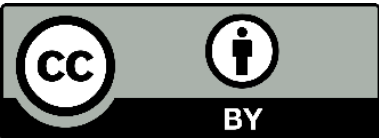

The Author(s). 2021 Open access This article is distributed under the terms of the Creative Commons Attribution 4.0 International License (https://creativecommons.org/licenses/by/4.0/), which permits unrestricted use, distribution, and reproduction in any medium, provided you give appropriate credit to the original author(s) and the source, provide a link to the Creative Commons license, and indicate if changes were made. 
On the other hand, it could also be connected to the seasonal variation in the infrasound wave travel path. In order to investigate this phenomenon, a temporary station called Infrasound IBHM was deployed $200 \mathrm{~km}$ west of I34MN station. Following one- year survey data (2017-2018) collected from the Baganuur open-pit mine which is active and located in the rural area, we analyzed the seismic and acoustic signals from the collected data.

\section{MATERIALS AND METHODS}

The Infrasound IBHM temporary station was installed in a forest area with the objective of reducing environmental noise. The station was deployed close to a place called Buregkhangai, which is located some $350 \mathrm{~km}$ west of the Baganuur open-pit mine. The infrasonic filters and sensors (MB2000 micro barometer) are connected between the tube with the ability to withstand 16 bar pressure and have been designed to filter noise reduction at the end of the prepared tube. This station consisted of a triangular configuration with a distance of 100 meters, each element array has four parts with eight input pipes.

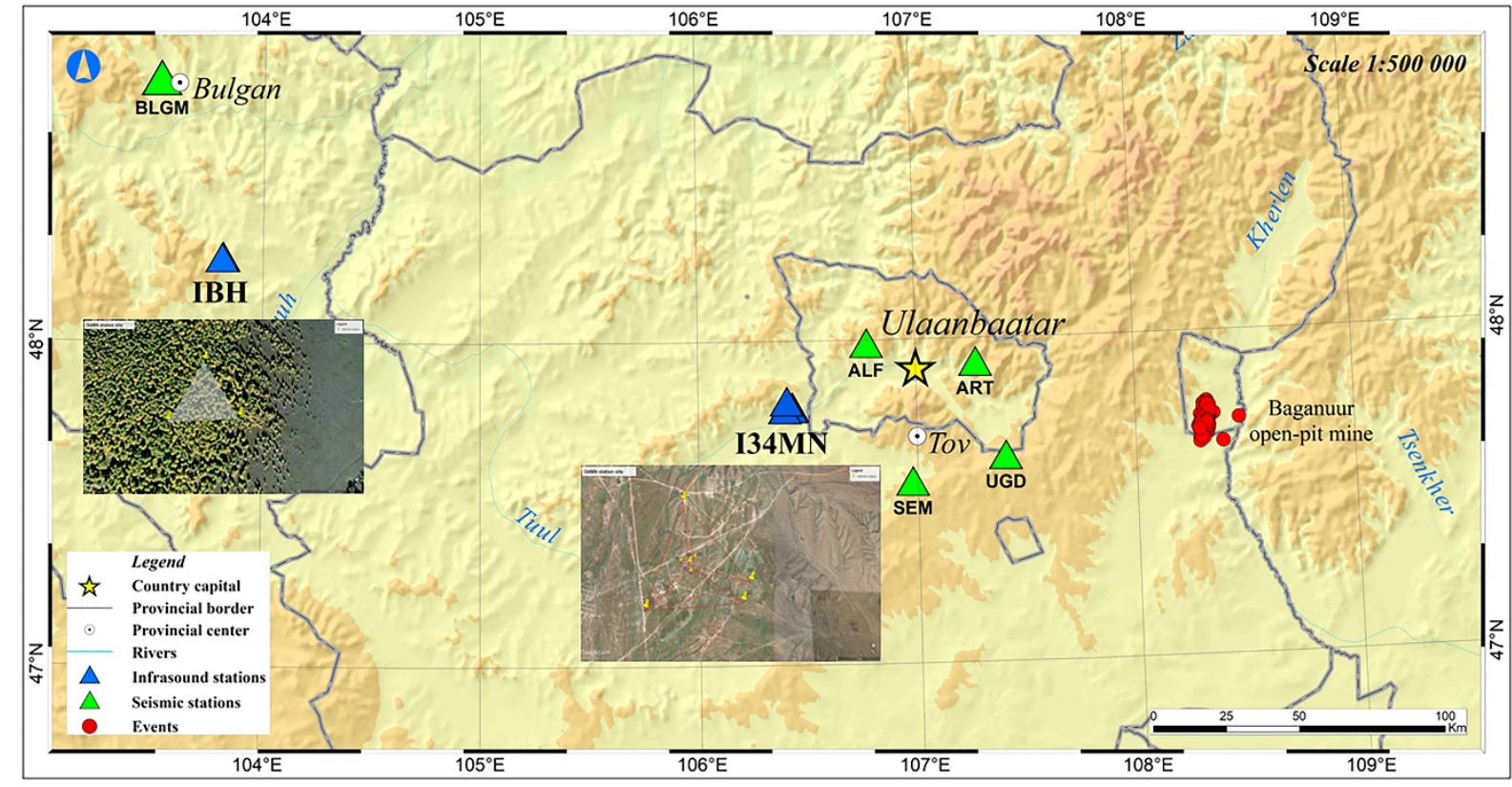

Figure 1. The location of permanent and temporary infrasound stations: the blue triangles are infrasound stations

The green triangles are seismic stations, red circles are events from the Baganuur open-pit mine blasts, the yellow star idepicts the capital city of Ulaanbaatar city respectively

The permanent I34MN infrasound station is located in a mountain valley some $150 \mathrm{~km}$ west of the Baganuur open-pit mine. Structurally, the outer elements (H5, H6, H7, $\mathrm{H} 8)$ are $1.5 \mathrm{~km}$, and inner elements $(\mathrm{H} 2, \mathrm{H} 3$, $\mathrm{H} 4)$ are $200 \mathrm{~m}$ from the center point (H1). The wind noise reduction array network consists of 4 sections with a steel pipe with 32 inlets for each element. IBHM station has three elements, sub-network $\mathrm{H} 2, \mathrm{H} 3$, and $\mathrm{H} 4$ were selected from I34MN station in order to maintain the same recording capacity of the station. 

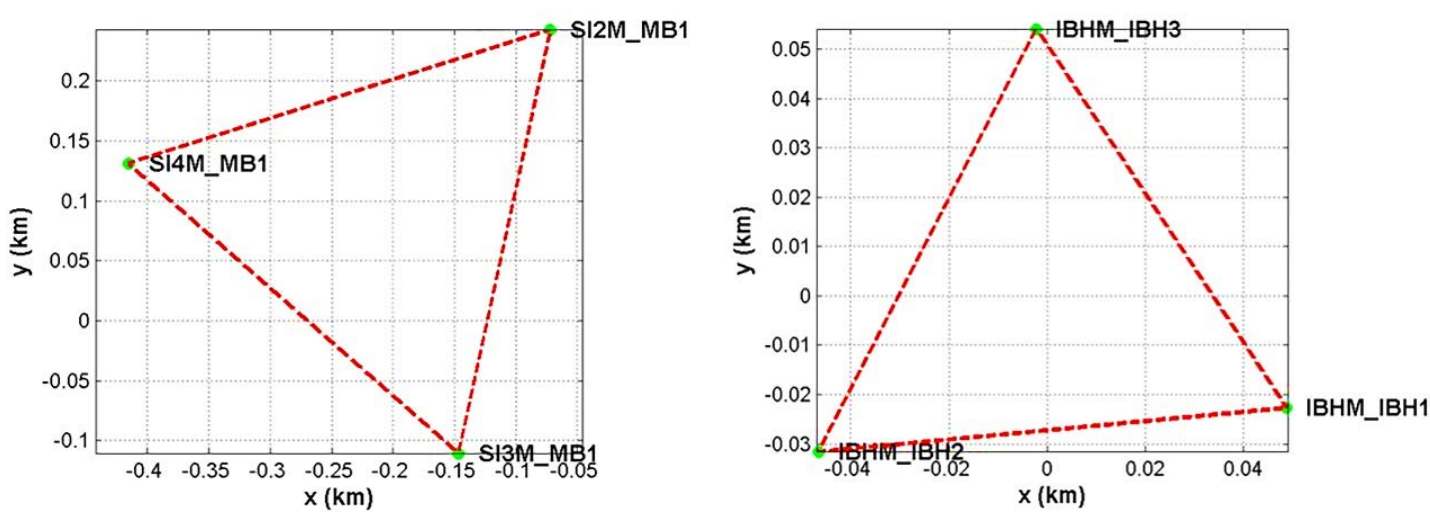

Figure 2. Element selection of I34MN and IBHM infrasound stations

We tested the detection capability of the temporary station by comparing it with a permanent station. For this purpose, every hour we calculated the daily data signal spectrum and averaged the data from both the permanent and temporary stations (Figure 2.) The result showed that the background noise level at the temporary station was on an average $20 \mathrm{~dB}$ lower than I34MN station for a frequency band up to $4 \mathrm{~Hz}$. There could be two reasons for this noise level difference. First, the permanent station is located $20 \mathrm{~km}$ west of the capital city of Ulaanbaatar, which has a population of more than 1 million. In this case, the city is becoming a major source of infrasound noise. Secondly, we installed the temporary station in a forest area protected from prevailing winds. Measurement of background micro-pressure and the wind generated noise during the experiment clearly showed that the forest areas are important criteria for reducing background noise in infrasound measuring.
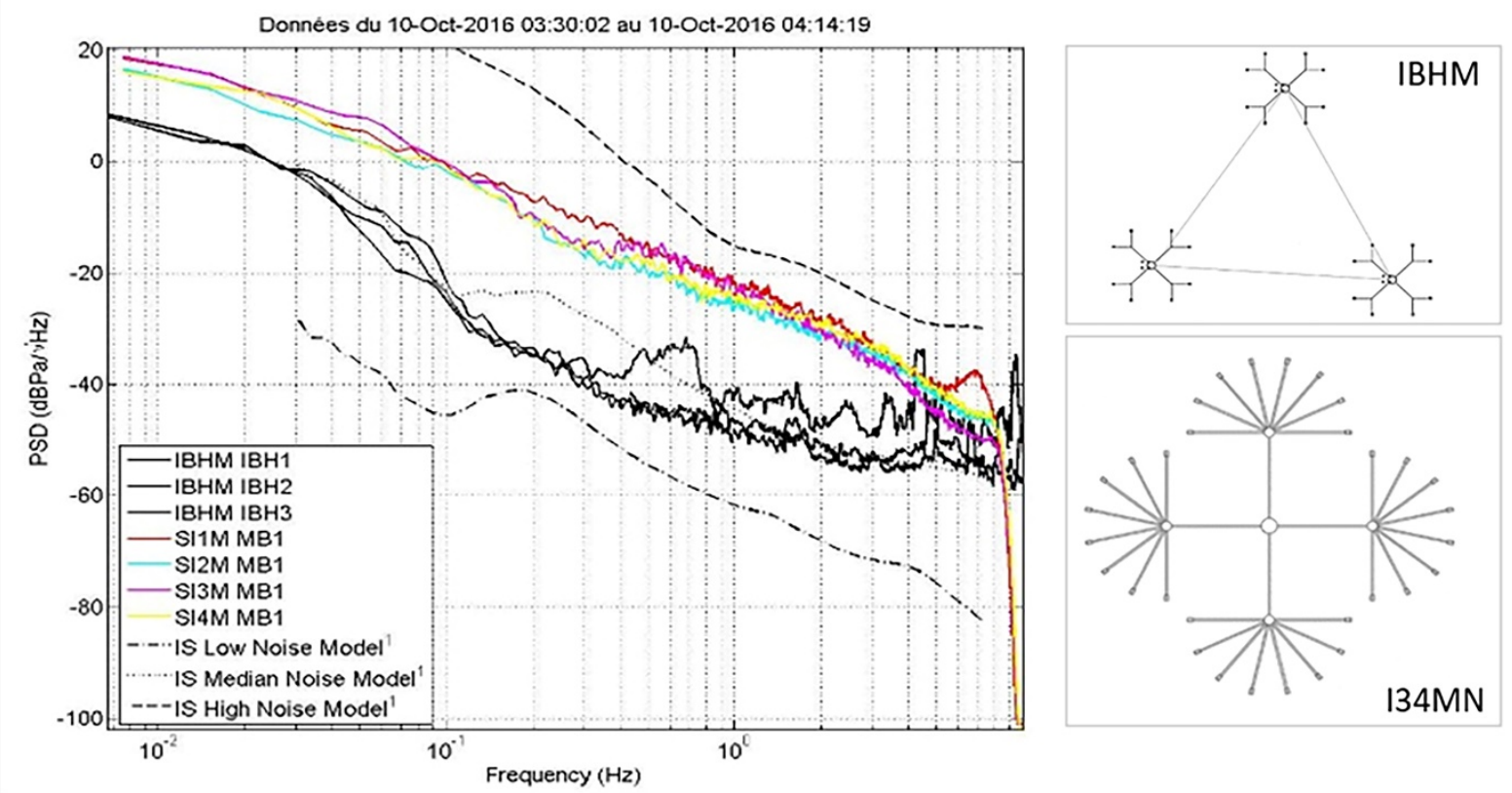

Figure 3. The noise level comparison of infrasound stations

I34MN station spectrum is plotted in color, and IBHM station spectrum is plotted in black. Spatial filtered design of IBHM and I34MN stations

PMCC algorithm: The Progressive Multichannel Correlation (PMCC) algorithm (Cansi 1995; Cansi and Klinger 1997) is used for infrasound data analysis to determine infrasound events azimuth and apparent velocity for filtered frequency ranges.

PMCC is a technique, which is based on the assumption of the validity of the plane wave 
signal model, which means that events are far enough from infrasound sensor arrays so that the arrays can treat the propagating infrasound signals as plane waves. The time delay in-plane wave arrival at one sensor relative to the other one can be calculated using cross-correlation of the two infrasound signals. Fourier transformation of a signal $s(t)$ can be represented in the frequency domain as

$$
s(f)=A(f) e^{i \varphi(f)}
$$

where $A(f)$ represents the spectral amplitude and $\varphi(f)$ is the spectral phase.

Given plane wave presence, the time shift at which the cross-correlation is at a maximum is as follows

$$
\Delta t_{i j}=\frac{1}{2 \pi f}\left(\varphi_{j}(f)-\varphi_{i}(f)\right)
$$

A plane wave produces a consistent set of time delays by

$$
\Delta t_{i j}+\Delta t_{j k}+\Delta t_{i k}=0
$$

satisfying what is known as the closure relation. Due to the background noise level, the crosscorrelation operation can have some uncertainties and the delays may not sum exactly to zero. The consistency of the set of time delays for $n$ sensors of sub-array $R_{n}$ is defined as the mean quadratic residual of the closure relation, expressed as follows:

$$
c_{n}=\sqrt{\frac{6}{n(n-1)(n-2)} r_{i j k}^{2}}
$$

where $\quad r_{i j k}=\Delta t_{i j}+\Delta t_{j k}+\Delta t_{i k} \quad$ and $i, j, k \in R_{n}$. If the calculated consistency is below an established threshold, i.e. tolerably close to zero, a detection is declared on $R_{n}$ [3][4].

\section{Data analysis}

Explosion data caused by human activity is easier to use as compared to other sources. This is because it is possible to use statistic information of mine blast to know the start time, the recurrence period, and the geographical location.

There are several large mines in Mongolia, the Baganuur mine area being the closest mine to the infrasound I34MN station. Mine blast events were detected and recorded at I34MN, IBHM infrasound, and PS25 seismic stations. The seismic signal generated by the mining blast was processed by ONYX software to determine the geographical location, the origin time, and the magnitude. Conspicuously to the processing, the Baganuur open-pit mine was blasted every week between 6 and 8 o'clock UTC, with an average magnitude of $\mathrm{ml}=2.0$, located within a range of $20 \mathrm{~km}$ longitude, and $5 \mathrm{~km}$ latitude.

In 2017, we have processed 174 seismic signals at the seismic station from the blasts at the Baganuur open-pit mine. During the winter months (February, March, and December), a total of 67 seismic signals were recorded, of which 22 (23) acoustic signals were from I34MN (IBHM) station, also duringthe summer months (June, July, and August), a total of 14 seismic signals were recorded, of which 3 (7) acoustic signals were from I34MN (IBHM) station in the course of the experiment.

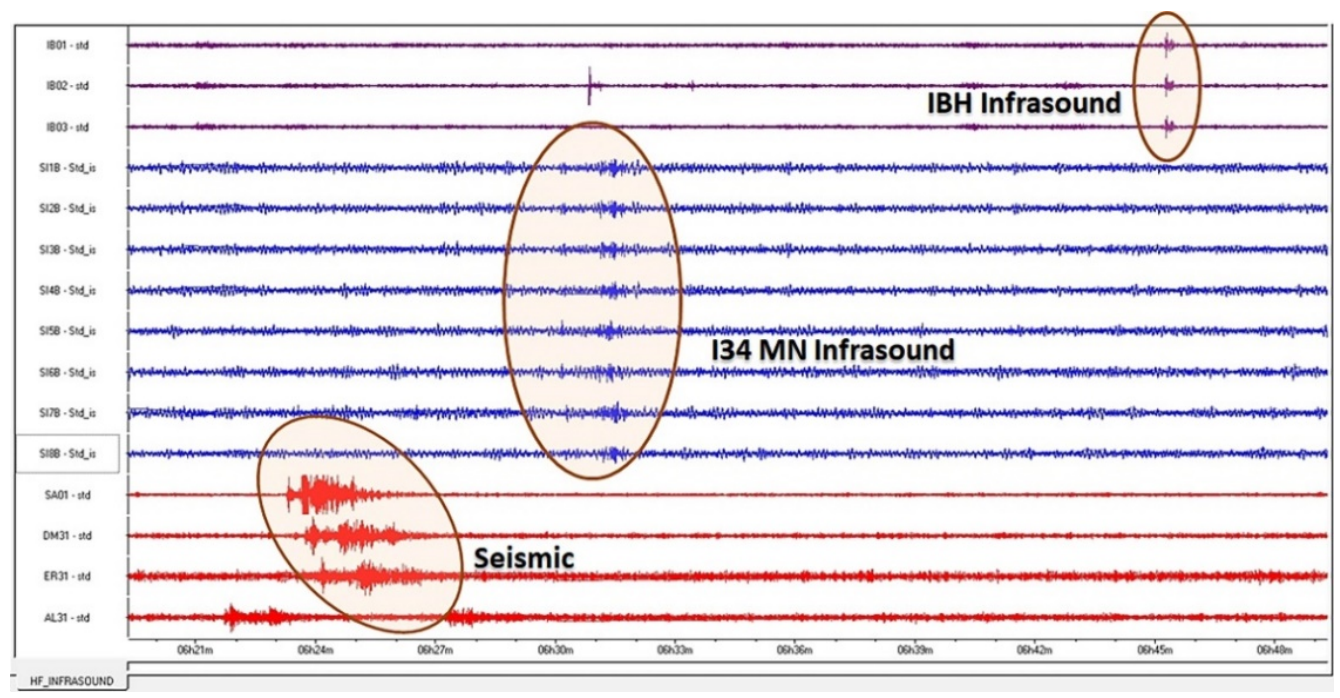

Figure 4. Detection of blast signals from Baganuur open-pit mine with infrasound and seismic stations recorded 
Automatic processing is "station processing", where the system attempts to detect signals and extract their characteristics (e.g., back azimuth, horizontal trace velocity, frequency content, amplitude, duration) at the individual stations using the Progressive MultiChannel Correlation (PMCC) algorithm [3][4].

For I34MN station, the explosions recorded frequency range was $1.5-2.5 \mathrm{~Hz}$, and the acoustic signal was recorded 8-9 minutes after a blast, at an average $0.334 \mathrm{~km} / \mathrm{s}$ speed, in the direction of 92-94 degrees.

For IBHM station, the recorded frequency range was $1.2-2.2 \mathrm{~Hz}$, and the acoustic signal was recorded 19-22 minutes after a blast, at an average $0.310 \mathrm{~km} / \mathrm{s}$ speed, in the direction of 99-101 degrees.

In addition, 1-2 minutes after the first acoustic signal from the blast, an acoustic signal with an average speed of $0.303 \mathrm{~km} / \mathrm{s}$ was detected at IBHM station from the same frequency range from the same direction [5].

Comparing the signals recorded at IBHM station, it was observed that the first recorded signal propagated at a lower speed through the thermosphere layer, while the later recorded signal propagated faster at the stratospheric layer.

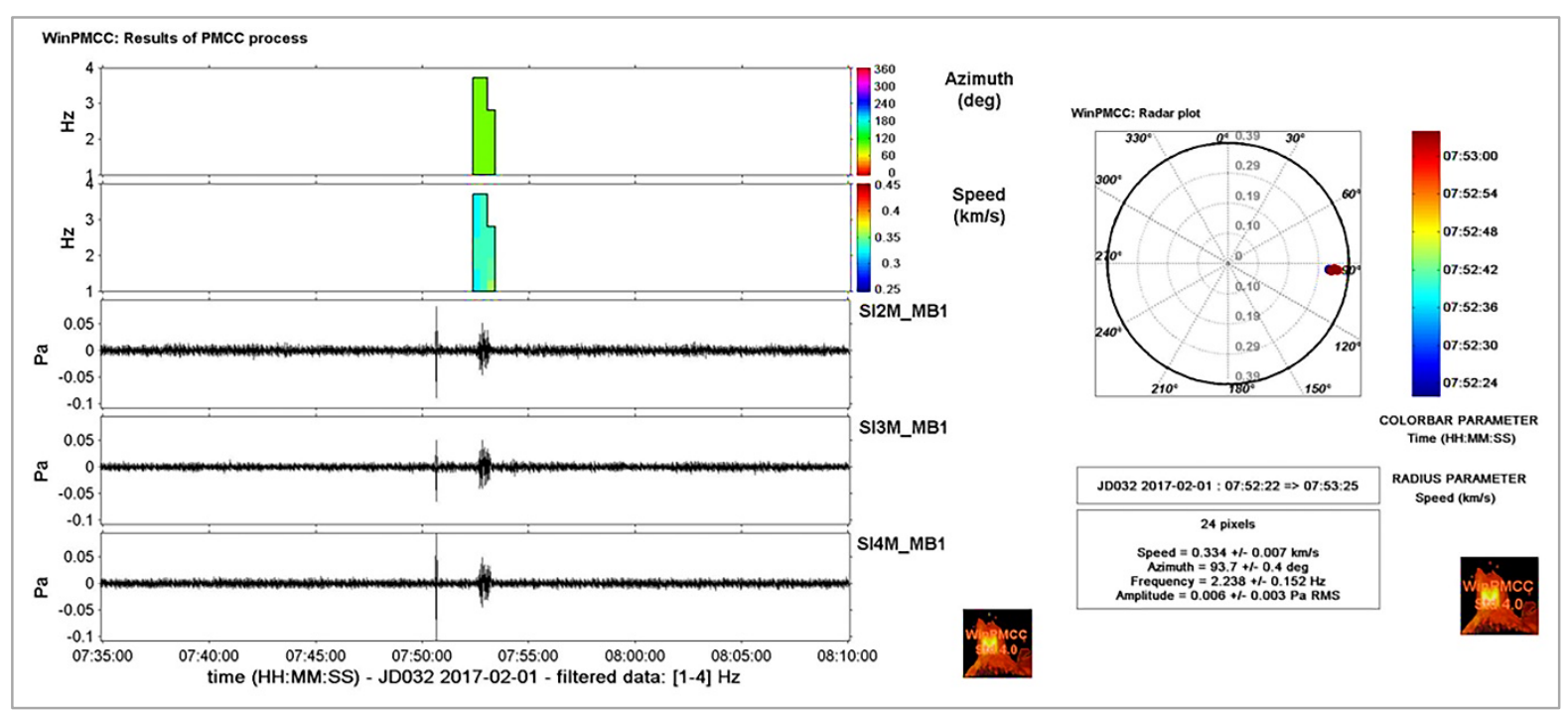

Figure 5. PMCC processing result. Two panels show azimuth and speed and the lower panels shows waveform data (filtered between $0.2 \mathrm{~Hz}$ and $4 \mathrm{~Hz}$ )

Detection of real infrasound on I34MN station on 02 February 2017 at 10:12:45

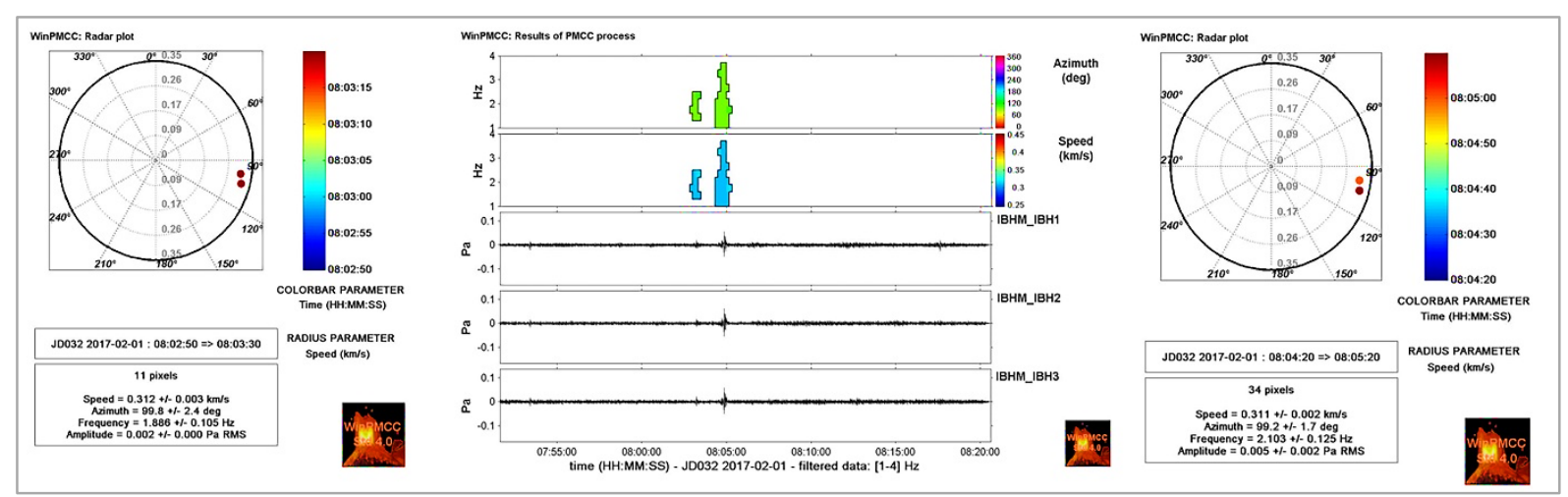

Figure 6. PMCC processing result. Two panels show azimuth and speed and the lower panels show waveform data (filtered between $0.2 \mathrm{~Hz}$ and $4 \mathrm{~Hz}$ )

Detection of real infrasound on IBHM station on 01 February 2017 at 08:02:50 and 08:04:20 


\section{RESULTS AND DISCUSSION}

A much more complete set of ray tracing can be obtained by using the InfraTaup GUI interface. InfraTaup generates a map of predicted bounce points, color-coded by group velocity, for the region specified by Lat limits and Lon limits [6].

The color map gives effective sound speed to the west and east of the source. Rays were integrated forward in time from a source location above the ground. When downward propagating ray made contact with the surface, the location and time of that contact was recorded. Rays that were ducted in the stratosphere and thermosphere are blue and red respectively.

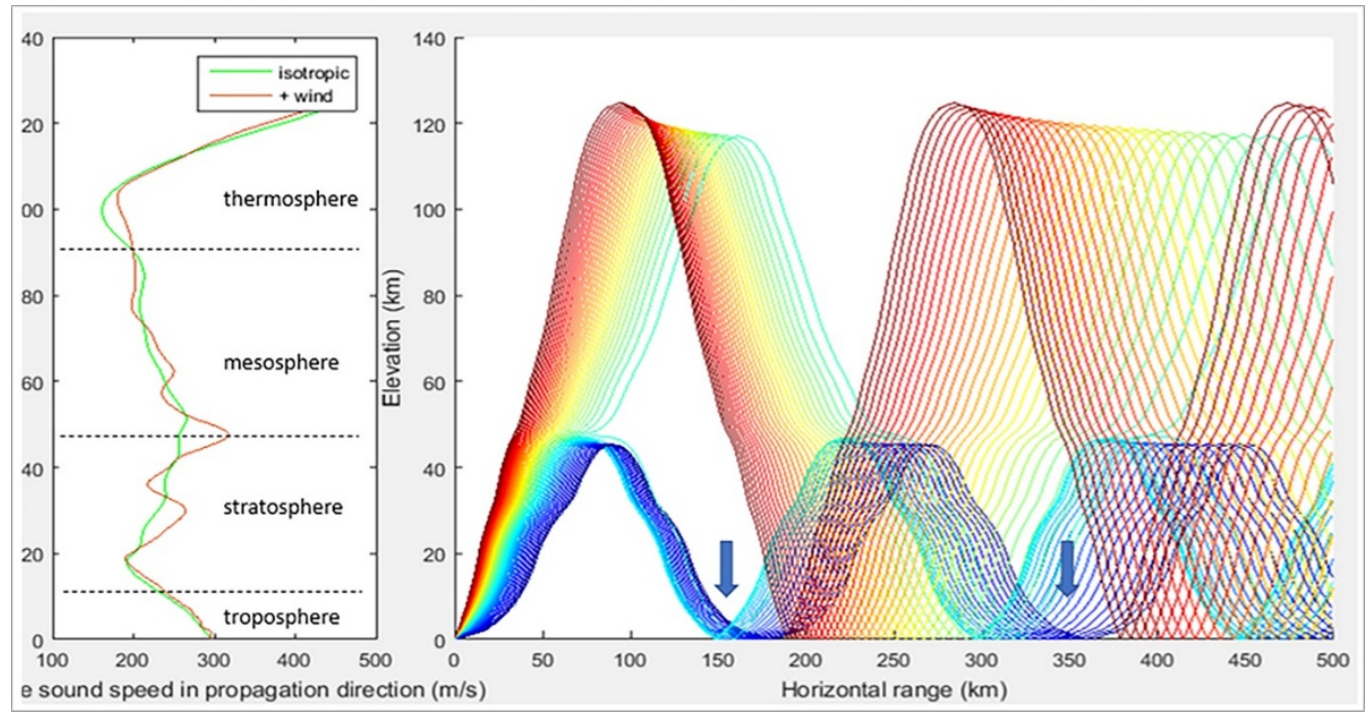

Figure 7. InfraTaup to generate a map of predicted bounce point, color-coded by group velocity, for the region specified by Lat limit and Lon limits

The result suggests that an acoustic signal from blasts at the Baganuur open-pit mine mostly propagates through the thermosphere in summer time, and less reflection on the

\section{CONCLUSIONS}

The results were obtained with short-term (one year) infrasound data. Through temporary installed infrasound IBH, we observed seasonal variation of infrasound noise level as previously detected on I34MN permanent infrasound station. The IBH station noise level was lower than the I34MN station with an average $20 \mathrm{~dB}$ for frequency band up to $4 \mathrm{~Hz}$. The measurements of background noise made during the experiment clearly showed that the location of forested area is an important criterion for reducing background noise in infrasound measuring. The forested area is stratosphere. However, in winter, I34MN detects and records the acoustic signals from blasts at the mine area which propagates through the stratosphere. possibly protected from wind and it is not expected to be affected by the shockwave.

Comparison of observed and calculated apparent velocities of Baganuur mine explosions infrasound signal suggested that Infrasound detection level of permanent station I34MN is dependent not only on seasonal variation issues, but also on infrasound wave propagation path itself.

In the future, long-term measurement over multiple years will be helpful in clarifying the seasonal variation of celerity and in studying the atmospheric effects on infrasound propagation. 
Acknowledgement: This work was possible thanks to the equipment provided by CEA-DASE and collaboration between IAG, and CEA-DASE. We also would like thank the engineering team of IAG for their support for deployment of mobile stations.

\section{REFERENCES}

1. A Le.Pichon, R.Matoza, N.Brachet, Y.Cansi (2010). "Resent enhancement of the PMCC infrasound signal detector”. CEA/DAM/DIF, F-91297 Arpajon, France, 5-8

2. Bayarsaikhan.Ch (2013), "Seismo acoustic analysis of I34MN for improvement of infrasound propagation modelling” $\mathrm{PhD}$ Dissertation (In Mongolian).

3. Tungalag.L, Bayarsaikhan.Ch., (2014) "Determination of power spectrum for Signal to Noise ratio", Proceedings of the Mongolian Academy of Sciences: Vol.54 №02.

4. $\quad$ N.Brachet, D.Brown et al, "Monitoring the Earth's Atmosphere with the Global IMS Infrasound Network", Book: A Le.Pichon, E.Blanc, A.Hauch (2010). Infrasound Monitoring for Atmospheric studies: pp77-118.
5. Anthony M.Runco Jr, James A. Louthain, Dean A. Clauter (2014) "Optimizing the PMCC algorithm for Infrasound” Open journal of Acoustic: pp204-213

6. Runco, Anthony M., "Detection Optimization of the Progressive MultiChannel Correlation Algorithm Used in Infrasound Nuclear Treaty Monitoring" (2013). Theses and Dissertations. 900. https://scholar.afit.edu/etd/900

7. Arrowsmith, S. J. and R. Whitaker (2008). InfraMonitor: A tool for regional infrasound monitoring, in Proceedings of the 30th Monitoring Research Review: Ground-Based Nuclear Explosion Monitoring Technologies, LA-UR-08-05261, pp.837-843. 